\title{
SABERES DO OUTRO NO LIVRO DIDÁTICO: A HISTÓRIA DOS AFRO-BRASILEIROS
}

\author{
THE OTHERNESS IN THE TEXTBOOK: THE AFRO- \\ BRAZILIAN HISTORY
}

\author{
Manoel Ayusso Martins* \\ Vânia de Fátima Martino*
}

\begin{abstract}
RESUMO: Neste trabalho, discute-se em que medida livros didáticos de História (8ํㅜ ano) se mostram abertos à diversidade cultural e às diferentes formas de existir, saber e estar no mundo. Para isso, são analisadas as características da história dos negros no Brasil veiculadas nas coleções "Nova História Crítica", "Projeto Araribá - História" e "História Sociedade \& Cidadania". Como referência, são utilizados documentos oficiais (Lei 10.639/03 e diretrizes curriculares) e a literatura sobre multiculturalismo e educação. Os resultados indicam que os princípios veiculados, que integram e consolidam construções eurocêntricas, representam os negros predominantemente em condições de marginalização (pobre, escravizado, etc.). Tais resultados evidenciam que (1) os autores não têm sido capazes de produzir livros didáticos multiculturalmente orientados, que (2) estes livros se apresentam como território fértil de reprodução do daltonismo cultural e das relações sociais de desigualdade e dominação que tal daltonismo produz, e que (3) há uma relação íntima entre formação acadêmica dos autores e o conteúdo multicultural dos livros.
\end{abstract}

Palavras-chave: Afro-brasileiros; Multiculturalismo; Livro didático.

ABSTRACT: In the following work, it is discussed how open to the cultural diversity and to the multiplicity of ways of existing, knowing and being at the world are the History textbooks ( $8^{\text {th }}$ year of schooling). It will be done through checking what are the principles of afro-brazilian history disseminated in these textbooks (New Critical History, Arariba History Project, History Society and Citizenship). The theoretical framework used is based on official documents (Law n. 10.639/03 and curricular guidelines) and on the literature of multiculturalism and education. The findings indicate that the principles disseminated in the textbooks integrate and consolidate eurocentric constructions because it develops the idea of the black people predominantly as marginalized (poor, enslaved, etc.). It confirms that (1) the authors have not been able to produce multiculturally oriented collections, that (2) the collections are fertile territories of reproduction of a cultural color blindness and its social relations of domination and

\footnotetext{
"Mestre em Planejamento e Análise de Políticas Públicas pela Universidade Estadual Paulista "Júlio de Mesquita Filho" (UNESP). Contato: manoel.a.martins@unesp.br

" Doutorado em Serviço Social pela Universidade Estadual Paulista "Júlio de Mesquita Filho" (UNESP). Docente da UNESP. Contato: vania.martino@unesp.br
} 
inequality, and that (3) there is a close connection between authors' academic background and the multicultural substance of the textbooks.

Keywords: Afro-brazilian; Multiculturalism; Textbook.

\section{INTRODUÇÃO}

Considerando-se a relevância de livros didáticos dentro e fora da sala de aula e como objeto da teorização em educação no Brasil (BITTENCOURT, 1993; DI GIORGI et al., 2014; FREITAG; MOTTA; COSTA, 1987; GATTI JÚNIOR, 2012; MUNAKATA, 2012), este trabalho está preocupado com a construção da história dos afro-brasileiros em livros didáticos de História (SCHMIDT, 2005; APOLINÁRIO, 2014; BOULOS JÚNIOR, 2017), atentando-se ao que tal construção têm a nos dizer sobre o tema da diversidade cultural e o lugar que ocupa nos níveis não oficiais de geração e desenvolvimento curricular, como editoras. Os estudos têm se preocupado com as representações dos negros no livro didático; com a detecção de estereótipos e distorções; com os impactos para educação de negros e negras na escola, incluindo-se a construção de identidades e a reprodução de padrões de dominação, violência e exclusão, como racismo; com a construção de currículo e contextos educacionais multiculturais; atentam-se também em verificar se livros didáticos têm atendido às exigências do Estado quanto aos princípios veiculados em textos e documentos oficiais (ANTUNES; NOGUEIRA, 2018; MÜLLER, 2015, 2018; ROSEMBERG; BAZILLI; SILVA, 2003; ROZA, 2015; SILVA, 2005; GOMES, 2012a).

Este estudo dá continuidade a estas perspectivas enfatizadas pela literatura, ao investigar a condição dos autores de livros didáticos, considerandose conceitos e valores que mobilizam, em produzir textos curriculares abertos à diversidade cultural que caracteriza a sociedade brasileira. Para isso, optamos em discutir aquilo que se circunscreve à questão dos negros. Trata-se de uma opção, um recorte, e enquanto tal carrega suas arbitrariedades. De forma alguma reflete qualquer ordem de importância. Poderíamos optar pela questão das 
mulheres, dos homossexuais, dos indígenas, dos deficientes, dos pobres, dos periféricos, dos camponeses, entre outras culturas negadas e silenciadas no currículo escolar (SANTOMÉ, 1995). A análise da construção da história dos afro-brasileiros leva em conta em que medida os textos didáticos têm veiculado princípios de valorização da identidade negra, entendidos (os princípios) em sua relação com os saberes e a produção cultural negros.

A lógica deste conceito (produção cultural negra) vincula-se à historicidade dos movimentos sociais negros no Brasil enquanto sujeitos de conhecimento que, a partir de determinado momento no cenário nacional, passaram a reivindicar-se como produtores de uma cultura própria (GOMES, 2012a, 2012b; GUIMARÃES, 2012). Entendemos que a temática dos negros se apresenta como termômetro considerável para se discutir a relevância que tem sido dada à questão da diversidade cultural no currículo. A análise debruça-se, portanto, sobre o processo de incorporação (ou não) de saberes negros ao conhecimento formal através da ação dos autores na produção de textos didáticos, partindo-se do pressuposto de que esta incorporação constitui caminho fundamental na construção de contextos e textos educacionais multiculturalmente orientados.

Apoiamo-nos nos textos da Lei de Diretrizes e Bases da Educação Nacional (BRASIL, 1996) (LDB), a partir das alterações que sofreu com a aprovação da Lei 10.639/03 (BRASIL, 2003), e das Diretrizes Curriculares Nacionais para Educação das Relações Étnico-Raciais e Ensino de História e Cultura Africana e Afro-Brasileira (DCNERER), instituídas a partir da Lei 10.639/03 em movimento no Conselho Nacional de Educação (CNE) do Ministério da Educação (MEC). E fundamentalmente apoiamo-nos nos conceitos emprestados da literatura sobre multiculturalismo e educação (SANTOMÉ, 1995; MOREIRA, 2001, 2002, 2020; CANEN; OLIVEIRA, 2002; MOREIRA; CANDAU, 2003; CANDAU, 2020; CANEN; ARBACHE; FRANCO, 2001).

A seguinte problemática, então, orientou a análise: quais são os princípios sobre a história dos afro-brasileiros veiculados nos livros didáticos? Neste sentido, objetivamos identificar (1) a quais elementos a história dos negros no 
Brasil é relacionada nos livros e (2) de que forma o livro didático dialoga com a construção de um currículo multicultural.

Logo abaixo (conceitos), apresentaremos o referencial teórico adotado, considerando-se problema e objetivos delimitados. Em seguida (metodologia), serão apresentados os procedimentos referentes à seleção das fontes e levantamento de dados. Depois (resultados), os dados serão matematizados e descritos. Por fim (discussão e conclusões), estes dados serão analisados à luz dos conceitos mobilizados.

\section{CONCEITOS}

Sustentamos este estudo na noção bernsteiniana de currículo: o que é veiculado (BERNSTEIN, 1975) ${ }^{1}$. Portanto, o conceito de currículo é aplicado aqui (a) à condição dos autores em produzir textos didáticos no âmbito editorial e (b) ao conteúdo (conceitos subjacentes) destes textos, não se estendendo, então, às relações sociais, práticas pedagógicas e avaliativas que se desenvolvem nas escolas a partir dos didáticos em movimento. Portanto, não são incluídas no horizonte conceitual as implicações do uso, por alunos e professores, dos textos em termos pedagógicos e avaliativos nas salas de aula. A ênfase deste trabalho está no lugar ocupado pela diversidade cultural no currículo. Como dito, será abordado em que medida as concepções e olhares dos autores dos textos didáticos dialogam com a construção de um currículo multicultural (MOREIRA, 2001, 2002, 2020).

Apoiamo-nos na premissa de que as sociedades ocidentais contemporâneas, incluindo-se a brasileira, são inegavelmente plurais e multiculturais, e de que a emergência deste fenômeno (caráter plural das sociedades - um dos múltiplos significados do conceito de multiculturalismo) enseja padrões de dominação específicos baseados em determinantes de classe, habilidade, etnia, religião, gênero, idade, linguagem, gostos e

\footnotetext{
1 Para Bernstein (1975), o conhecimento educacional é realizado através de três sistemas de mensagens: currículo (o que deve ser transmitido e adquirido), pedagogia (como deve ser transmitido e adquirido) e avaliação (realizações esperadas de quem adquire).
} 
identificações, etc. Neste mosaico, as diferenças culturais e identitárias acabam se tornando vias de hierarquização, posicionando-se "eu" e "outro" em condições de desigualdade e produzindo-se fenômenos como marginalização, violência e opressão (CANEN; OLIVEIRA, 2002; MOREIRA; CANDAU, 2003; MOREIRA, 2001, 2002). Sob esta ótica, entendemos que há demandas e conflitos que emergem na estrutura empírica destas sociedades multiculturais e devem ser objeto de atenção das artes, da literatura, de movimentos sociais, do Estado, da educação escolar, da produção acadêmica, etc. Trata-se de problema ao qual podem ser oferecidas diferentes respostas, mas que não pode ser ignorado. Obviamente, entendemos que todas as respostas oferecidas em diferentes territórios são válidas, desde que orientadas multiculturalmente.

Do diálogo entre esta premissa e o objeto delimitado emerge a ideia, carregada por nós, de que o currículo, oficial ou recontextualizado², deve obrigatoriamente oferecer respostas compatíveis a estas demandas e conflitos, e deve abrir caminhos rumo ao questionamento dos referidos padrões de dominação e desigualdade. No centro desta argumentação, então, reside a noção de que a educação deve vir a ser uma educação multicultural e o currículo deve vir a ser um currículo multiculturalmente orientado. E, para isso, deve haver um movimento de desestabilização dos cânones epistemológicos e culturais que inundam a formação docente, os distintos níveis de geração e desenvolvimento curricular, e as questões pedagógicas e avaliativas, e que transformam a escola em espaço monocultural e daltônico, incapaz de assimilar a variedade e complexidade das culturas que a atravessam e constituem (MOREIRA; CANDAU, 2003; CANDAU, 2020; MOREIRA, 2001, 2002, 2020).

Retomamos, para exemplificar um destes movimentos de desestabilização na educação, a ação do Estado através da Lei 10.639/03 e do texto curricular que a representa (DCNERER). A LDB, em seu artigo 26, parágrafo 4 , dispõe sobre a necessidade de o ensino contemplar as "[...] contribuições das diferentes culturas e etnias para a formação do povo brasileiro,

\footnotetext{
${ }^{2} \mathrm{O}$ currículo oficial está sob influência do Estado. O currículo recontextualizado refere-se ao discurso oficial em movimento e modificado pelas relações de poder na educação (BERNSTEIN, 1996). No caso dos livros didáticos de História, trata-se do discurso recontextualizado.
} 
especialmente das matrizes indígenas, africana e europeia." (BRASIL, 1996); e as DCNERER objetivam o reconhecimento e valorização da "identidade, história e cultura dos afro-brasileiros", ressaltando-se seu "jeito próprio de ser, viver e pensar" (MEC, 2004, p. 11-12) ${ }^{3}$. Situamos estes documentos no âmbito de "[...] diretrizes legais e parâmetros curriculares que incorporam a diversidade cultural e/ou linguística e que trazem, para o interior da escola, questões antes envoltas por uma névoa de silêncio ou dissimulação." (CANEN; ARBACHE; FRANCO, 2001, p. 164). Trata-se de movimento que sintetiza e expressa visivelmente as preocupações multiculturais do Estado.

Dito isto, destacamos a responsabilidade dos autores diante deste movimento de desestabilização, na direção da construção de um currículo multiculturalmente orientado em níveis não oficiais, como editoras. Responsabilidade anunciada, inclusive, nos referidos documentos oficiais. Desta forma, para que haja respostas consideradas (no recorte deste artigo e das referências mobilizadas) adequadas, entendemos que os autores devem ser capazes de "reescrever o conhecimento escolar" (MOREIRA, 2020, p. 35), e uma das formas de fazê-lo é oferecendo abertura às múltiplas formas de existir, de pensar o mundo e estar nele. Este reconhecimento no âmbito do currículo constitui resposta urgente a cenários de complexidade cultural, pois abre caminhos para (a) realizar conceitos de diversidade cultural, (b) construir identidades e sujeitos culturais híbridos, e (c) reconhecer que a anulação desta multiplicidade de saberes não se trata de algo natural, dado, universal, mas sim construído, e, portanto, imerso em princípios de poder (MOREIRA; CANDAU, 2003; CANDAU, 2020; CANEN; ARBACHE; FRANCO, 2001; GOMES, 2012a). É à luz desta lógica que o "outro" (aqui, afro-brasileiros e sua produção cultural) é visto não como algo a ser conhecido, mas sim como sujeito conhecedor.

\footnotetext{
${ }^{3}$ A literatura sobre a Lei e sua própria documentação oficial (MEC, 2004) caracterizam-na como política de ação afirmativa. As ações afirmativas constituem medida interventiva do Estado, fundada em recortes étnicos e identitários, que, segundo Candau (2020) e Moreira (2002), é potencialmente eficaz em sociedades multiculturais. Para leituras mais amplas sobre 0 conceito de ação afirmativa e a complexidade de sua natureza, ver Domingues (2005), Moehlecke (2016), Piovesan (2008) e Silvério (2007).
} 
Dentre os vários elementos responsáveis por inviabilizar este quadro, produzindo escola e currículo daltônicos e monoculturais, estão as representações, apontadas de forma enfática pela literatura, dos negros e de sua história a partir de ausências, distorções e apagamentos; situações de desprestígio social; descaracterizações e esvaziamento identitários. O negro está sempre associado à miséria, fome, barbárie, violência, e o branco sempre associado à cidadania e civilização. Estes dados contribuem para reprodução de ideologias do branqueamento, para inferiorização e marginalização de determinados grupos, e para consolidação de relações sociais de desigualdade social e cultural (evasão de jovens negros, racismo, violência, disparidade de acesso a recursos materiais e simbólicos, auto rejeição, etc.) (SILVA, 2005).

Dito isto, ansiamos, com a análise, discutir como os autores têm contribuído para consolidar uma ou outra realidade.

\section{MÉTODOS}

Foram escolhidas as coleções "Nova História Crítica” (SCHMIDT, 2005)", "Projeto Araribá - História" (APOLINÁRIO, 2014) e "História Sociedade \& Cidadania" (BOULOS JÚNIOR, 2017) ${ }^{6}$. As três referem-se à $7^{\text {ạ }}$ série/8ํㅜ ano do período escolar, momento em que o estudo de africanidades se mostra bastante evidente. Sua seleção seguiu fundamentalmente dois critérios: relevância da coleção e formação acadêmica de seus autores. Entendemos que os dados sobre a formação acadêmica dos autores nos ofereceriam mais elementos para discutir sua condição de produzir livros didáticos multiculturalmente orientados ou não. Em relação à primeira questão, pautamo-nos pelas informações enviadas pelo Ministério da Educação sobre os livros didáticos de História mais escolhidos pelas escolas brasileiras (MEC, 2018). Assim, pudemos optar por aqueles de maior tiragem e que, consequentemente, estiveram presentes em mais unidades escolares.

\footnotetext{
${ }^{4}$ Livro Didático 1 (LD1).

${ }^{5}$ Livro Didático 2 (LD2).

${ }^{6}$ Livro Didático 3 (LD3).
} 
Segundo o MEC, foram distribuídas às escolas 824.992 unidades do LD1, em 2005, tendo sido gasto pelo Fundo Nacional de Desenvolvimento da Educação (FNDE) um valor total de R\$ 5.222.199,36. Quanto ao LD2, foram distribuídas em 2014684.412 unidades, tendo sido gasto um valor total de $\mathrm{R} \$$ 4.633.469,24. E, por fim, em relação ao LD3, foram distribuídas 831.760 unidades em 2017, tendo sido gasto um valor total de $\mathrm{R} \$ 7.394 .346,40$ (MEC, 2018).

No que diz respeito à formação acadêmica, foram feitos levantamentos na plataforma tradicional do Google e no Currículo Lattes. Mário Furley Schmidt, autor do LD1, não possui graduação em História, ou em qualquer outra área, comprovada. Fato curioso, inclusive, refere-se às polêmicas, há cerca de uma década atrás, sobre seu "sumiço" após exigências feitas pelo Programa Nacional do Livro Didático (PNLD) referentes à titulação de autores de livros didáticos comprados pelo Estado (FERNANDES, 2007). Os autores do LD2 (autoria coletiva) são graduados em História e mestres em História ou Educação. E Alfredo Boulos Júnior, autor do LD3, é doutor em Educação, com pesquisa em relações raciais na educação.

Em relação aos procedimentos realizados, o trabalho é amparado por uma metodologia mista, na qual coexistem aspectos quantitativos e qualitativos. As porcentagens foram utilizadas como norte para a análise orientada pelos conceitos apresentados.

O tema, utilizado como unidade de análise, corresponde ao conteúdo escrito dos livros didáticos, portanto, à "fala do autor", tendo sido selecionadas todas e quaisquer menções e referências feitas à história dos negros no Brasil. Primeiramente, os temas foram sistematizados e organizados em categorias iniciais, a partir de seus elementos constituintes em comum. Em seguida, estas categorias iniciais foram agrupadas em categorias mais amplas e representativas, denominadas molares (FRANCO, 2005; BARDIN, 1977). A frequência das categorias molares, em cada coleção, foi calculada em função da quantidade de vezes que todas as categorias iniciais apareceram e da quantidade de vezes que as categorias iniciais correspondentes às categorias molares apareceram. 
As coleções foram analisadas individualmente, considerando-se a mensagem global disciplinar, ignorando-se, portanto, suas especificidades internas (tópicos, divisões, unidades, etc.). Ao todo foram organizados quatro quadros. O Quadro 1 descreve a frequência das categorias molares do LD1. O Quadro 2 descreve a frequência das categorias molares do LD2. O Quadro 3 descreve a frequência das categorias molares do LD3. E, por fim, o Quadro 4 compara as frequências das categorias molares dos LD 1, 2 e 3, destacando-se sua relação com a formação acadêmica dos respectivos autores.

\section{RESULTADOS}

Sobre o LD1 ("Nova História Crítica"):

As categorias iniciais emergentes são: 1. Negros como escravizados e exescravizados. 2. Conflitos entre abolicionistas e escravistas. 3. Contexto nacional caracterizado pela escravidão. 4. Violência praticada contra os negros escravizados e ex-escravizados. 5. Resquícios da escravização nos negros. 6. Participação ativa do movimento abolicionista na sociedade brasileira. 7 . Valorização de particularidades culturais dos negros no Brasil. 8. Negros em funções sociais relevantes. 9. Resistência dos negros escravizados e exescravizados. 10. Integração entre diferentes grupos étnicos. 11. Racismo no Brasil. As categorias iniciais 1, 2, 3, 4, 5 e 6 foram agrupadas na categoria molar História dos negros no Brasil associada a posições de inferioridade (CM1). As categorias iniciais 7, 8 e 9 foram agrupadas na categoria molar História dos negros no Brasil associada à sua produção cultural (CM2). E as categorias iniciais 10 e 11 foram agrupadas na categoria molar História dos negros no Brasil associada às relações sociais entre negros e brancos (CM3). 
Quadro 1 - Frequência das categorias molares do LD1

\begin{tabular}{|c|c|}
\hline Categorias molares & Frequência \\
\hline CM1 & $75,7 \%$ \\
\hline CM2 & $13,5 \%$ \\
\hline CM3 & $10,6 \%$ \\
\hline
\end{tabular}

Fonte: Elaborado pelos autores a partir da análise de Schmidt (2005).

Foi possível verificar que os negros e sua história no Brasil são associados de forma predominante a posições de inferioridade, nomeadamente a escravidão $(75,7 \%)$. Isto significa dizer que parcela significativa da coleção os representa como sujeito dominado, cujo patrimônio é pensado em função da condição de escravizado e ex-escravizado. Simultaneamente, em frequência consideravelmente menor, são posicionados enquanto produtores culturais $(13,5 \%)$, sendo sua história relacionada aos saberes e conhecimentos que produzem e às suas formas de pensar o e estar no mundo. E, por fim, em frequência ainda menor, os negros são posicionados em um quadro mais amplo de relações sociais entre negros e brancos (10,6\%), discorrendo-se sobre os fenômenos resultantes de uma constituição étnica plural no Brasil, a exemplo do racismo.

Quando consideramos os negros construídos como escravizados, devese destacar que, apesar de todas as categorias iniciais remeterem a um lugar comum (de dominação, no qual o negro é esvaziado de qualquer identidade que não seja a de escravo), há críticas e denúncias, quase sempre explícitas e declaradas, deste lugar. Exemplo disto é o destaque dado pelo autor às inúmeras formas de violência e maltrato sofridas pelos escravizados e ao fato de tais formas produzirem heranças vividas até os dias atuais. Quando consideramos os negros construídos como produtores de uma cultura que nos inunda cotidianamente até os dias de hoje, há três abordagens direcionadoras. A primeira refere-se às contribuições variadas que os negros ofereceram ao Brasil historicamente; a segunda os pensa em funções sociais relevantes e de destaque na política, no mundo das artes e das letras; e a terceira os pensa na 
condição de protagonistas de levantes, insurreições e manifestações populares por motivos diversos, como resistência à escravização e às condições de vida precárias, denúncias contra formas diversas de violência, etc. Por fim, quando consideramos os negros construídos como parte de um quadro mais amplo de relações entre negros e brancos no Brasil, há uma presença muito tímida de categorias que apontam para uma democracia racial marcada por interações harmônicas (identidade nacional, etc.). Predominantemente, estas interações são pensadas em função dos conflitos que ensejam, como o racismo.

Sobre o LD2 ("Projeto Araribá - História”):

As categorias iniciais emergentes são: 1. África como extensão das relações e interesses políticos e econômicos no Brasil. 2. Negros como escravizados e ex-escravizados. 3. Negros em situações sociais desfavorecidas. 4. Contexto nacional caracterizado pela escravidão. 5. Violência praticada contra os negros escravizados e ex-escravizados. 6. Conflitos entre abolicionistas e escravistas. 7. Resquícios da escravização nos negros. 8. Participação ativa do movimento abolicionista na sociedade brasileira. 9. Contexto internacional caracterizado pelo tráfico de escravos e sua influência na sociedade brasileira. 10. Valorização de particularidades culturais dos negros no Brasil. 11. Resistência dos negros escravizados e ex-escravizados. 12. Negros em funções sociais relevantes. 13. Descendentes de quilombolas como mantenedores de saberes ancestrais negros. 14. Integração entre diferentes grupos étnicos. 15. Hierarquias sociais descritas a partir das relações sociais entre negros e brancos. 16. Racismo no Brasil. 17. Ações do Estado voltadas ao combate do racismo. As categorias iniciais 1, 2, 3, 4, 5, 6, 7, 8 e 9 foram agrupadas na categoria molar História dos negros no Brasil associada a posições de inferioridade (CM1). As categorias iniciais 10, 11, 12 e 13 foram agrupadas na categoria molar História dos negros no Brasil associada à sua produção cultural (CM2). E as categorias iniciais 14, 15, 16 e 17 foram agrupadas na categoria 
molar História dos negros no Brasil associada às relações sociais entre negros e brancos (CM3).

Quadro 2 - Frequência das categorias molares do LD2

\begin{tabular}{|c|c|}
\hline Categorias molares & Frequência \\
\hline CM1 & $72,8 \%$ \\
\hline CM2 & $18,6 \%$ \\
\hline CM3 & $8,4 \%$ \\
\hline
\end{tabular}

Fonte: Elaborado pelos autores a partir da análise de Apolinário (2014).

Da mesma forma que no LD1, no LD2, os negros e sua história também são predominantemente associados a posições de inferioridade e dominação (72,8\%). Assim, as representações mais comuns os constroem enquanto sujeito escravizado, pobre e/ou marginalizado. Em frequência menor, são posicionados enquanto produtores culturais $(18,6 \%)$, de modo que sua história no Brasil é relacionada aos seus saberes e formas de se relacionar com o mundo. E, por fim, são posicionados em um quadro mais amplo de relações sociais entre negros e brancos (8,4\%), abordando-se questões como o racismo e a consequente necessidade da formulação de ações afirmativas no âmbito da educação, saúde, trabalho, etc.

Quando consideramos os negros construídos como escravizados, verifica-se no LD2 uma mesma tendência presente no LD1: apesar de todas as categorias iniciais remeterem ao lugar comum de marginalização, muitas destas categorias imprimem críticas a este lugar. Há nos autores do LD2, da mesma forma que no autor do LD1, uma preocupação em denunciar o impacto da escravidão sobre os negros historicamente e suas heranças até os dias atuais. Quando consideramos os negros construídos como produtores culturais, enfatiza-se a diversidade cultural do continente africano e a influência desta diversidade na formação étnica brasileira (costumes e tradições), e também há referências aos descendentes de quilombolas no Brasil atualmente, abordando-se suas formas de pensar e se relacionar com o mundo. Por fim, 
quando consideramos os negros construídos como parte de um quadro de relações entre negros e brancos, também é tímida a presença de categorias que retomam a ideia de democracia racial. As categorias apontam predominantemente para os conflitos fundados em recortes étnicos, como o racismo e a desigualdade de acesso a recursos materiais e simbólicos, destacando-se a necessidade de políticas afirmativas no Brasil, mencionandose cotas raciais e a própria Lei 10.639/03.

\section{Sobre o LD3 ("História Sociedade \& Cidadania")}

As categorias iniciais emergentes são: 1. Descaracterização identitária dos negros escravizados. 2. Escravidão na África como extensão do contexto internacional caracterizado pelo tráfico de escravos e sua influência no Brasil. 3. Negros como escravizados e ex-escravizados. 4. África como extensão de relações e interesses políticos e econômicos no Brasil. 5. Violência praticada contra os negros escravizados e ex-escravizados. 6. Contexto nacional caracterizado pela escravidão. 7. Negros em situações sociais desfavorecidas. 8. Conflitos entre abolicionistas e escravistas. 9. Participação ativa do movimento abolicionista na sociedade brasileira. 10. Resquícios da escravização nos negros. 11. Contexto internacional caracterizado pelo tráfico de escravos e sua influência no Brasil. 12. Negros em funções sociais relevantes. 13. Descendentes de quilombolas como mantenedores de saberes ancestrais negros. 14. Valorização de particularidades culturais dos negros no Brasil. 15. Resistência dos negros escravizados e ex-escravizados. 16. Resistência dos escravizados e ex-escravizados como produtora de saberes negros no Brasil. 17. Movimento negro como elemento de combate ao racismo no Brasil. 18. Negros como protagonistas do movimento abolicionista. 19. Relevância de tradições e saberes ancestrais negros no Brasil atualmente. 20. Integração entre diferentes grupos étnicos. 21. Racismo no Brasil. 22. Hierarquias sociais descritas a partir das relações sociais entre negros e brancos. As categorias iniciais $1,2,3,4,5,6,7,8,9,10$ e 11 foram agrupadas na categoria molar História dos negros no Brasil associada a posições de inferioridade (CM1). As 
categorias iniciais $12,13,14,15,16,17,18$ e 19 foram agrupadas na categoria molar História dos negros no Brasil associada à sua produção cultural (CM2). E as categorias iniciais 20, 21 e 22 foram agrupadas na categoria molar História dos negros no Brasil associada às relações sociais entre negros e brancos (CM3).

Quadro 3 - Frequência das categorias molares do LD3

\begin{tabular}{|c|c|}
\hline Categorias molares & Frequência \\
\hline CM1 & $50,3 \%$ \\
\hline CM2 & $39 \%$ \\
\hline CM3 & $10,6 \%$ \\
\hline
\end{tabular}

Fonte: Elaborado pelos autores a partir da análise de Boulos Júnior (2017).

No LD3, há diferenças visíveis em relação ao LD1 e LD2, conforme as porcentagens apontam. No entanto, os negros ainda são associados de forma majoritária a posições de inferioridade e dominação (50,3\%), sendo sua história representada em contextos de escravização, marginalização e pobreza. Em frequência próxima (e isto caracteriza a diferença entre LD1, 2 e 3), são posicionados enquanto produtores culturais (39\%), e seu patrimônio é relacionado às suas formas de existir gestadas a partir de suas experiências e tradições no Brasil, em estreita relação com o continente africano. E, por fim, em frequência consideravelmente menor (10,6\%), são pensados em um quadro mais amplo de relações sociais entre negros e brancos, discutindo-se fenômenos decorrentes de uma constituição étnica plural no Brasil, como o racismo.

Quando consideramos os negros construídos como escravizados, verifica-se no LD3 a mesma tendência presente nos LD1 e 2: apesar de todas as categorias iniciais remeterem ao lugar comum de marginalização, muitas destas categorias imprimem críticas a este lugar. O autor do LD3 amplia esta discussão, trazendo questões já trazidas pelos autores dos LD1 e 2, como a violência praticada contra os escravizados, mas também incluindo outras, como 
a descaracterização identitária do negro escravizado. Quando consideramos os negros construídos como produtores culturais, há diferenças ainda mais visíveis, de modo que as categorias são mais frequentes e muito mais ecléticas do que nos outros documentos (LD1 e 2). Há uma preocupação explícita, inclusive declarada pelos pareceristas do Guia de Avaliação do PNLD 2017 (MEC, 2016), do autor com a história dos africanos e afro-brasileiros.

A valorização de particularidades culturais do negro no Brasil expõe a riqueza e a influência das tradições e costumes trazidos da África, destaca a diversidade constituinte do continente africano e os impactos de tal diversidade na constituição étnica brasileira. O negro em função social relevante o representa enquanto político, funcionário público, intelectual, advogado, jornalista, poeta. Sobre os descendentes de quilombolas, é falado sobre as heranças deixadas pelos negros quilombolas resistentes à escravização e seus impactos nas formas de vida atuais neste lugares (quilombos). Considerando-se os três LD analisados, o LD3 é o único em que a categoria que constrói o negro escravizado como resistente à escravização é mais frequente que a categoria que o contrói como escravizado e subalternizado. Outras categorias inéditas são o movimento negro como elemento de combate ao racismo no Brasil e os valores e saberes ancestrais negros como constituintes de práticas e hábitos no Brasil atual. $\mathrm{O}$ primeiro apresenta o papel da imprensa, de entidades e associações utilizadas pelos negros como formas de manifestação e reivindicação de direitos historicamente, a exemplo de grupos de lazer, clubes esportivos, centros religiosos. Apresenta, também, o papel do movimento negro contemporâneo no Brasil, desde 1970, nas reivindicações diante de situações e contextos de precariedade que atingem a população negra atualmente.

Por fim, quando consideramos os negros construídos como parte do quadro de relações sociais entre negros e brancos, não há elementos significativos que diferenciem o LD3 dos LD1 e 2. Há um predomínio de categorias que discutem essa questão a partir dos conflitos ensejados pela pluralidade da constituição étnica e cultural no Brasil, como racismo e formas diversas de violência, e uma presença insignificante de categorias que pensam esta constituição étnica a partir de interações harmônicas (democracia racial). 
Quadro 4 - Comparação entre coleções e formação acadêmica dos autores

\begin{tabular}{|c|c|c|}
\hline Coleções & Categorias molares & $\begin{array}{c}\text { Formação acadêmica } \\
\text { do(s) autor(es) }\end{array}$ \\
\hline \multirow{2}{*}{ LD1 } & CM1: $75,7 \%$ & $\begin{array}{c}\text { Sem graduação } \\
\text { comprovada }\end{array}$ \\
& CM2: $13,5 \%$ & $\begin{array}{c}\text { Graduados em História } \\
\text { e mestres em História }\end{array}$ \\
\hline LD2 & CM1: $72,8 \%$ & ou Educação \\
\hline CM2: $18,6 \%$ & CM3: $8,4 \%$ & Doutor em Educação \\
& (relações raciais na \\
& CM1: $50,3 \%$ & educação) \\
\hline
\end{tabular}

Fonte: Elaborado pelos autores a partir da análise de Schmidt (2005), Apolinário (2014) e Boulos Júnior (2017).

Quando as coleções são comparadas em função de seus respectivos autores (aspectos ligados à formação acadêmica), é possível perceber que o LD1, cujo autor não possui graduação comprovada, é aquele no qual a CM1 demonstra-se mais presente (75,7\%), e a CM2 menos (13,5\%). Segue-se o LD2, cujos autores são graduados em História e mestres em História ou Educação, no qual a CM1 demonstra-se menos presente e a CM2 demonstra-se mais presente em comparação ao LD1. Por fim, o LD3, cujo autor é doutor em Educação, é aquele no qual a CM1 demonstra-se menos presente (50,3\%), e a CM2 mais (39\%). A CM3 se mantém quase igual nos LD1, 2 e 3.

\section{DISCUSSÃO E CONCLUSÕES}

A partir das análises desenvolvidas, entendemos que os princípios sobre a história dos negros no Brasil veiculados nos livros didáticos de História integram e consolidam construções eurocêntricas de mundo. É possível notar que (1) as narrativas norteadoras, apesar de suas especificidades em cada 
coleção, como demonstrado, representam predominantemente a história dos negros no Brasil como objeto da história europeia, de modo que as concepções de civilização, cultura, tempo, desenvolvimento, etc., são fundamentalmente europeias, e que (2) os negros ainda são predominantemente representados como marginalizados, seja como pobre ou escravizado. Isto significa que os autores das coleções não têm sido capazes de reescrever o conhecimento escolar na direção da abertura a diferentes formas de existir, estar e interpretar o mundo. As concepções e valores que mobilizam caminham na direção oposta à construção de um currículo multiculturalmente orientado, ao passo que se verifica a marginalização dos saberes negros como construtores e interventores válidos da realidade. Entendemos, portanto, que não é possível caracterizar as coleções como territórios onde a diversidade cultural é representada, e nem como territórios onde as relações sociais de desigualdade e dominação produzidas pelas diferenças culturais são questionadas ou discutidas, apesar das iniciativas visualizadas.

Como dito anteriormente, o reconhecimento da existência de múltiplas formas de saber e conhecer constitui resposta urgente da educação a cenários de complexidade cultural, e a predominância de movimento oposto a esta necessidade atribui aos livros didáticos, e ao nível onde são produzidos (editoras), alcunha de território fértil de reprodução do daltonismo cultural, de ideologias do branqueamento (SILVA, 2005), e de relações de desigualdade e dominação. A título de comparação e exemplo, vale destacar a dissonância entre os textos oficiais mencionados anteriormente, que representam a Lei 10.639/03, e os textos didáticos. Isto demonstra que os didáticos, no que diz respeito ao seu conteúdo escrito, continuam a distribuir valores e princípios que o Estado, no espectro de suas preocupações multiculturais, tenta desestabilizar. Trata-se de planos e direções opostas: enquanto o currículo oficial dá vida a um movimento de valorização do patrimônio histórico e cultural africano e afro-brasileiro e de combate ao racismo, o currículo recontextualizado (livros didáticos de História) reproduz estereótipos e caricaturas.

No entanto, deve ser destacado, apesar de não haver um movimento significativo de incorporação da produção cultural negra ao currículo, as 
coleções não são totalmente vazias deste conteúdo multicultural. Há iniciativas dos autores, principalmente no LD3, de tornar central a questão dos negros no que diz respeito à sua cultura, saberes e às mazelas às quais são historicamente submetidos. No entanto, estas iniciativas ainda esbarram na predominância de princípios que perpetuam construções eurocêntricas. E sobre estas iniciativas, chamamos atenção para a relação entre formação acadêmica - conteúdo produzido.

No que diz respeito aos LD1 e 2, entendemos haver relação, apesar de não tão visível ou significativa. Ambos apresentam dados bastante semelhantes referentes à forma como representam a história dos negros no Brasil, mas divergentes referentes aos seus respectivos autores. No entanto, no LD2, cujos autores são graduados e mestres, em comparação ao LD1, cujo autor não possui graduação comprovada, há um alargamento dos princípios ligados à produção cultural negra e uma redução dos princípios ligados a posições de inferioridade. E este alargamento é ainda mais expressivo no que diz respeito ao LD3, cujo autor é doutor em educação, com pesquisa em relações raciais na educação. No caso do LD3, entendemos ter havido uma influência mais significativa da formação acadêmica no conteúdo produzido. Apesar de os princípios ligados a posições de inferioridade e dominação ainda serem predominantes ante os demais, os dados indicam uma notória atenção do autor à questão dos negros, demonstrando uma tentativa visível de representar sua história no Brasil sob óticas alternativas àquelas anteriores observadas. Ao nosso ver, isto indica uma relação íntima entre preocupações multiculturais dos autores e sua proximidade com a linguagem acadêmica.

Ora, isto representa um problema sério. Afinal, não devemos esperar que apenas autores especialistas na temática possam estar aptos a produzir informações que assumam uma direção multicultural, não?! Como, então, licenciaturas, bacharelados e pós-graduação podem auxiliar nesta questão? A literatura sobre multiculturalismo e educação aqui mobilizada é enfática ao apontar a relevância da formação docente na preparação de profissionais capazes de lidar com o arco-íris de culturas que atravessam e constituem os cotidianos escolares. Uma formação que ofereça condições aos profissionais 
para lidar com as múltiplas bagagens, experiências e formas de saber, entender e se relacionar com o mundo trazidas para o interior da escola. Neste sentido, entendemos que esta formação deve ser direcionada não somente ao profissional que lida diariamente com esta multiplicidade nas escolas, mas também àquele responsável pela produção dos materiais didáticos que serão direcionados a tais escolas. Caso isto não ocorra, estaremos fadados a aceitar milhares de textos, em circulação e uso, incapazes de traduzir a realidade brasileira tal qual é: multicultural e constituída por distintos e contraditórios significados e identidades. Estes mesmos textos, usados também fora das escolas (DI GIORGI et al., 2014), reforçam as relações sociais de desigualdade entre brancos e negros reveladas nos dados trazidos por Santos (2007) sobre Índice de Desenvolvimento Humano (IDH), renda, educação, esperança de vida no Brasil. O problema vai muito além dos muros da escola.

Além da questão da formação, outros questionamentos emergem aos nossos olhos e não podem ser ignorados. Questionamentos estes que demonstram quão complexo é o problema. Por que os autores, apesar das iniciativas visualizadas e mencionadas, não têm sido capazes de reescrever o conhecimento escolar na direção da construção de currículos multiculturalmente orientados? Por que os princípios veiculados persistem como construções eurocêntricas e como vias de silenciamento dos saberes e produção cultural negros? Há heranças do campo primário (família, comunidade) trazidas pelos autores que podem ter influenciado os valores e concepções mobilizados? Como os interesses políticos e mercadológicos das editoras influenciam os conteúdos produzidos pelos autores? Como mencionado, foi possível visualizar que se trata de direções opostas quando são considerados o currículo oficial (Estado - Lei 10.639/03 e DCNERER) e o currículo recontextualizado (livros didáticos de História). Quais os limites, então, para a ação de políticas educacionais de caráter multicultural? Em que medida o Estado, em suas preocupações multiculturais, tem sido incapaz de oferecer soluções válidas para este problema?

A caminho do fim, concluímos que os resultados aqui apresentados são preocupantes, quando consideramos que os LD1, 2 e 3 foram os textos didáticos 
mais escolhidos pelas escolas brasileiras. Considerando-se o potencial formador do livro didático de História e considerando-se que as coleções aqui analisadas referem-se ao $8^{\circ}$ ano do Ensino Fundamental II, entendemos que há muito a ser rediscutido e refeito. Assim, os autores devem incontestavelmente repensar prioridades e estar atentos às reais demandas do ensino básico e às suas funções diante de tais demandas. Não devemos esperar que apenas autores doutores em educação, com pesquisas específicas em relações raciais na educação, possam estar aptos a produzir informações que assumam a direção esperada de reconstrução da história dos afro-brasileiros para construção de currículo multicultural. Para que isso aconteça, é preciso que os autores o queiram, e também, obviamente, que sejam preparados para isso. No entanto, é fundamental lembrar de que isto não depende única e exclusivamente dos autores e de sua formação, já que livros didáticos são textos sob o poder de comercialização de editoras, havendo, por exemplo, interesses mercadológicos intrínsecos; dentre outros fatores.

\section{REFERÊNCIAS}

ANTUNES, Joelma Cristina de Lima; NOGUEIRA, Claudete de Sousa.

Representações de negros e indígenas nos livros didáticos no contexto das Leis 10.639 e 11.645: mudanças e permanências. Revista da Associação Brasileira de Pesquisadores/as Negros/as (ABPN), [S.I.], v. 10, n. ed. esp., p. 749-769, jun. 2018. Disponível em:

<https://abpnrevista.org.br/index.php/site/article/view/469/523>. Acesso em: 15 nov. 2018.

APOLINÁRIO, Maria Raquel (Ed.). Projeto Araribá - História: 8oano. 3. ed. São Paulo: Moderna, 2014.

BARDIN, Laurence. Análise de conteúdo. Lisboa: Edições 70, 1977.

BERNSTEIN, Basil. Class, codes and control: Towards a theory of educational transmissions. London: Routledge \& Kegan Paul, 1975. v. 3.

BERNSTEIN, Basil. A estruturação do discurso pedagógico: classe, código, controle. Petrópolis: Vozes, 1996. 
BITTENCOURT, Circe Maria Fernandes. O livro didático e o conhecimento histórico: uma história do saber escolar. 1993. 369 f. Tese (Doutorado em História) - Faculdade de Filosofia, Letras e Ciências Humanas, Universidade de São Paulo, São Paulo, 1993. Disponível em:

<https://repositorio.ufsc.br/handle/123456789/208387>. Acesso em: 10 set. 2017.

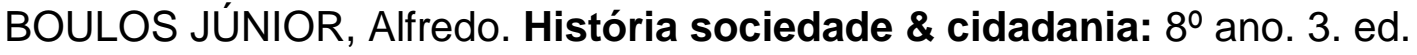
São Paulo: FTD, 2017.

BRASIL. Lei n. 9.394, de 20 de dezembro de 1996. Estabelece as diretrizes e bases da educação nacional. Diário Oficial da União, Brasília, DF, Seção 1, p. 27833, 23 dez. 1996. Disponível em: <http://www.planalto.gov.br/ccivil 03/leis/L9394.htm>. Acesso em: 16 jul. 2017.

BRASIL. Lei n. 10.639, de 09 de janeiro de 2003. Altera a Lei no 9.394, de 20 de dezembro de 1996, que estabelece as diretrizes e bases da educação nacional, para incluir no currículo oficial da Rede de Ensino a obrigatoriedade da temática "História e Cultura Afro-Brasileira", e dá outras providências. Diário Oficial da União, Brasília, DF, Seção 1, p. 1, 10 jan. 2003. Disponível em: <http://www.planalto.gov.br/ccivil 03/leis/2003/L10.639.htm>. Acesso em: 16 jul. 2017.

CANDAU, Vera Maria Ferrão. Didática, Interculturalidade e formação de professores: desafios atuais. Revista Cocar, Belém, n. 8, p. 28-44, jan./abr. 2020. Disponível em:

<https://periodicos.uepa.br/index.php/cocar/article/view/3045>. Acesso em: 20 abr. 2021.

CANEN, Ana; ARBACHE, Ana Paula; FRANCO, Monique. Pesquisando multiculturalismo e educação: o que dizem as dissertações e teses. Educação

\& Realidade, Porto Alegre, v. 26, n. 1, p. 161-181, jan./jul. 2001. Disponível em: <https://seer.ufrgs.br/educacaoerealidade/article/view/41321/26151>.

Acesso em: 20 abr. 2021.

CANEN, Ana; OLIVEIRA, Angela M. A. Multiculturalismo e currículo em ação: um estudo de caso. Revista Brasileira de Educação, Rio de Janeiro, n. 21, p. 61-74, set./dez. 2002. Disponível em:

<https://www.scielo.br/j/rbedu/a/QF4wH5r85zzy9hkYKjFDNNB/?format=pdf\&lan g=pt>. Acesso em: 20 abr. 2021.

DI GIORGI, Cristiano Amaral Garboggini et al. Uma proposta de aperfeiçoamento do PNLD como política pública: o livro didático como capital cultural do aluno/família. Ensaio: Avaliação e Políticas Públicas em Educação, Rio de Janeiro, v. 22, n. 85, p. 1027-1056, out./dez. 2014. Disponível em: <http://hdl.handle.net/11449/180464>. Acesso em: 15 mar. 2019. 
DOMINGUES, Petrônio. Ações afirmativas para negros no Brasil: o início de uma reparação histórica. Revista Brasileira de Educação, Rio de Janeiro, n. 29, p. 1-14, maio/ago. 2005. Disponível em:

<https://www.scielo.br/j/rbedu/a/g9K3wSLyhKn88LXn3GgJDvc/?format=pdf\&lan $\mathrm{g}=\mathrm{pt}>$. Acesso em: 17 jun. 2017.

FERNANDES, Nelito. O mistério do professor Schimdt. Época, São Paulo, n. 490, 5 out. 2007. Sociedade. Disponível em:

<http://revistaepoca.globo.com/Revista/Epoca/0,,EDG79463-6014-490,00O+MISTERIO+DO+PROFESSOR+SCHIMIDT.html>. Acesso em: 11 mar. 2019.

FRANCO, Maria Laura Puglisi Barbosa. Análise de conteúdo. 2. ed. Brasília, DF: Liber Livro, 2005.

FREITAG, Barbara; MOTTA, Valéria Rodrigues; COSTA, Wanderly Ferreira. 0 estado da arte do livro didático no Brasil. Brasília, DF: INEP: REDUC, 1987. Disponível em:

<http://www.dominiopublico.gov.br/download/texto/me001994.pdf>. Acesso em: 20 jul. 2017.

GATTI JÚNIOR, Décio. Entre políticas de estado e práticas escolares: uma história do livro didático no Brasil. In: STEPHANOU, Maria; BASTOS, Maria Helena Camara. (org.). Histórias e memórias da educação no Brasil: vol. III: século XX. Petrópolis: Vozes, 2012. p. 379-400.

GOMES, Nilma Lino. Relações étnico-raciais, educação e descolonização de currículos. Currículo Sem Fronteiras, [S.I.], v. 12, n. 1, p. 98-109, jan./abr. 2012a. Disponível em:

$<$ https://www.curriculosemfronteiras.org/vol12iss1articles/gomes.pdf>. Acesso em: 10 dez. 2019.

GOMES, Nilma Lino. Movimento negro e educação: ressignificando e politizando a raça. Educação \& Sociedade, Campinas, v. 33, n. 120, p. 727744, jul./set. 2012b. Disponível em: <https://old.scielo.br/pdf/es/v33n120/05.pdf>. Acesso em: 07 nov. 2019.

GUIMARÃES, Antonio Sérgio A. Preconceito racial: modos, temas e tempos. São Paulo: Cortez, 2012.

MEC. Conselho Nacional de Educação. Parecer CNE/CP n. 003/2004.

Diretrizes Curriculares Nacionais para a Educação das Relações Étnico-Raciais e para o Ensino de História e Cultura Afro-Brasileira e Africana. Diário Oficial da União, Brasília, DF, 19 maio 2004. Disponível em:

<http://portal.mec.gov.br/dmdocuments/cnecp 003.pdf>. Acesso em: 16 jul. 2017. 
MEC. PNLD 2017: história: ensino fundamental anos finais. Brasília, DF, 2016. Disponível em: <http://www.fnde.gov.br/component/k2/item/8813-guia-pnld2017>. Acesso em: 17 abr. 2019.

MEC. [Sistema Acesso a Informação]. Mensagem recebida por <manoel.amartins@yahoo.com>em 17 abr. 2018.

MOEHLECKE, Sabrina. Ações afirmativas no Brasil: um histórico do seu processo de construção. In: FONSECA, Marcus Vinicius; BARROS, Surya Aaronovich Pombo de. (org.). A história da educação dos negros no Brasil. Rio de Janeiro: Eduff, 2016.

MOREIRA, Antonio Flávio Barbosa. A recente produção científica sobre currículo e multiculturalismo no Brasil (1995-2000): avanços, desafios e tensões. Revista Brasileira de Educação, Rio de Janeiro, n. 18, p. 65-81, set./dez. 2001.Disponível em:

<https://www.scielo.br/j/rbedu/a/zXL3fYg89Xrh4jQRJWXGydd/?format=pdf>. Acesso em: 21 abr. 2021.

MOREIRA, Antonio Flávio Barbosa. Currículo, diferença cultural e diálogo. Educação \& Sociedade, Campinas, v. 23, n. 79, p. 15-38, ago. 2002. Disponível em: <https://www.scielo.br/j/es/a/xdrtMKTjRk7KmNTr9VwJK3q/?format=pdf\&lang=pt>. Acesso em: 21 abr. 2021.

MOREIRA, Antonio Flávio Barbosa. Currículo, diálogo e práticas pedagógicas. Educação e Cultura Contemporânea, Rio de Janeiro, v. 17, n. 50, p. 30-39, 2020. Disponível em: <http://periodicos.estacio.br/index.php/reeduc/article/view/8428/47967199>. Acesso em: 21 abr. 2021.

MOREIRA, Antonio Flávio Barbosa; CANDAU, Vera Maria. Educação escolar e cultura(s): construindo caminhos. Revista Brasileira de Educação, Rio de Janeiro, n. 23, p. 156-168, maio/ago. 2003. Disponível em: <https://www.scielo.br/j/rbedu/a/99YrW4ny4PzcYnSpVPvQMYk/?format=pdf>. Acesso em: 21 abr. 2021.

MÜLLER, Tânia Mara Pedroso. A produção acadêmica sobre a imagem do negro no livro didático: estado do conhecimento (2003-2013). In: REUNIÃO NACIONAL DA ANPED, 37., 2015, Florianópolis. Anais.... Florianópolis:

Anped, 2015. Disponível em: <http://37reuniao.anped.org.br/wpcontent/uploads/2015/02/Trabalho-GT21-3684.pdf>. Acesso em: 07 jul. 2019. 
MÜLLER, Tânia Mara Pedroso. Livro didático, educação e relações étnicoraciais: o estado da arte. Educar em Revista, Curitiba, v. 34, n. 69, p. 77-95, maio/jun. 2018. Disponível em:

$<$ https://www.scielo.br/j/er/a/q8Fc6KBmPsnWp6h9kh5mhtG/?format=pdf\&lang= pt>. Acesso em: 07 jul. 2019.

MUNAKATA, Kazumi. O livro didático como mercadoria. Pro-Posições, São Paulo, v. 23, n. 3(69), p. 51-66, set./dez. 2012. Disponível em:

<http://www.scielo.br/pdf/pp/v23n3/04.pdf>. Acesso em: 11 mar. 2019.

PIOVESAN, Flávia. Ações afirmativas no Brasil: desafios e perspectivas.

Estudos Feministas, Florianópolis, v. 16, n. 3, p. 887-896, set./dez. 2008.

Disponível em:

<https://www.scielo.br/j/ref/a/JXPnmdcRhtfnnv8FQsVZzFH/?format=pdf\&lang=pt>. Acesso em: 18 nov. 2019.

ROSEMBERG, Fúlvia; BAZILLI, Chirley; SILVA, Paulo Vinícius Baptista da. Racismo em livros didáticos brasileiros e seu combate: uma revisão de literatura. Educação e Pesquisa, São Paulo, v. 29, n. 1, p. 125-146, jan./jun. 2003. Disponível em:

<https://www.scielo.br/j/ep/a/Dw9cqwCczcddHVZjv3TnYGt/?lang=pt\&format=pdf>. Acesso em: 15 out. 2019.

ROZA, Luciano Magela. Valorização de personagens negros como conteúdo curricular no livro didático de história. Atos de Pesquisa em Educação, Blumenau, v. 10, n. 1, p. 123-149, jan./abr. 2015. Disponível em: <https://proxy.furb.br/ojs/index.php/atosdepesquisa/article/view/4575/2940>. Acesso em: 10 jul. 2019.

SANTOMÉ, Jurjo Torres. As culturas negadas e silenciadas no currículo. In: SILVA, Tomaz Tadeu. (org.). Alienígenas na sala de aula: uma introdução aos estudos culturais em educação. Petrópolis: Vozes, 1995. p. 159-189.

SANTOS, Sales Augusto dos. Introdução. In: SANTOS, Sales Augusto dos. (org.). Ações afirmativas e o combate ao racismo nas Américas. Brasília, DF: SECCAD, 2007. p. 15-31. Disponível em:

<https://etnicoracial.mec.gov.br/images/pdf/publicacoes/acoes afirm combate racismo americas.pdf >. Acesso em: 10 nov. 2019.

SCHMIDT, Mário Furley. Nova história crítica: $7^{a}$ série. São Paulo: Nova Geração, 2005. 
SILVA, Ana Célia da. A desconstrução da discriminação no livro didático. In: MUNANGA, Kabengele. (org.). Superando o racismo na escola. 2. ed. rev. Brasília, DF: MEC: SECAD, 2005. p. 21-37. Disponível em:

$<$ http://portal.mec.gov.br/secad/arquivos/pdf/racismo escola.pdf>. Acesso em: 5 mar. 2019.

SILVÉRIO, Valter Roberto. Ações afirmativas e diversidade étnico-racial. In: SANTOS, Sales Augusto dos. (org.). Ações afirmativas e o combate ao racismo nas Américas. Brasília, DF: SECAD, 2007. p. 141-164. Disponível em: $<$ https://etnicoracial.mec.gov.br/images/pdf/publicacoes/acoes afirm combate racismo americas.pdf>. Acesso em: 10 nov. 2019.

Recebido em: 06/09/2021

Aprovado em: 10/11/2021 